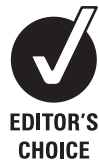

Allergy and Respiratory Research Group, Centre of Population Health Sciences: GP Section, University of Edinburgh, Edinburgh, Scotland, UK

Correspondence to: Dr H Pinnock, Allergy and Respiratory Research Group, Centre of Population Health Sciences: GP Section, University of Edinburgh, 20 West Richmond Street, Edinburgh EH8 9DX, Scotland, UK hilary.pinnock@ed.ac.uk

Received 19 May 2008 Accepted 18 December 2008

\title{
Primary care research and clinical practice: respiratory disease
}

\author{
H Pinnock, A Sheikh
}

\section{ABSTRACT}

Primary care respiratory research has contributed to the evidence base for both the clinical care of common longterm respiratory conditions and the management of acute respiratory illness. Key areas include investigating the role of remote consultations in ensuring regular professional reviews for people with asthma, understanding and evaluating the use of technology to support patient selfcare, exploring aspects of the shift of services for longterm conditions from secondary to primary care, investigating primary care prescribing using computerised databases of anonymised medical records, and tackling inequalities in provision of care for ethnic minorities. Further research will be needed in all these areas as the ongoing and increasing challenge of providing support for people with long-term conditions will demand innovative approaches to organisation of care, many of which will involve or be led by primary care.

In the UK, respiratory disease is responsible for more primary care consultations than any other type of illness. ${ }^{1}$ The 24 million respiratory consultations (an average of 1.8 per patient per year) and 51 million prescriptions issued annually encompass both ongoing care for people with long-term conditions, such as asthma and chronic obstructive pulmonary disease (COPD), and advising patients with acute, often self-limiting infections.

Underlying these statistics is a substantial mortality and morbidity attributable to respiratory disease. ${ }^{1}$ Surveys of people with asthma have consistently shown unacceptably poor control, associated with low expectations on the part of patients, ${ }^{23}$ and often underestimated by professionals. ${ }^{4}$ People with severe COPD have multiple, extensive and prolonged needs, ${ }^{5-7}$ with considerable socioeconomic impact on the lives of both patients and their carers. ${ }^{8}$ There is currently evidence of a substantial unmet need representing a major challenge for healthcare services.?

Pyramids of care, whether in the context of chronic disease" or acute "chest infections", 10 emphasise the significant role of primary care in managing the majority of people with these conditions. High-quality research, focusing on primary care management, is therefore fundamental to understanding and developing a comprehensive healthcare service for respiratory disease.

In 1996, the recognition of this need inspired the General Practice Airways Group to establish a chair of primary care respiratory medicine based at the University of Aberdeen, which aims to provide "primary care solutions to primary care problems". ${ }^{11}$ In collaboration with colleagues from the subsequently formed International Primary Care Respiratory Group, research agendas for asthma, COPD, smoking cessation, infectious diseases and allergic rhinitis have been developed and described. ${ }^{12}$

In this review, we discuss five key areas where UK primary care research has addressed important questions facing primary care (table 1).

\section{PROFESSIONAL REVIEWS OF PEOPLE WITH ASTHMA}

The provision of regular professional reviews to support patients managing their long-term condition is a key recommendation of asthma guidelines. ${ }^{13}{ }^{14}$ Primary care has responded to this need with pioneering work in the mid-1980s, ${ }^{15}{ }^{16}$ which led to the inclusion of asthma clinics in the 1990 General Medical Services contract. ${ }^{17}$ Such was the uptake of this initiative that by 1995 Jones and Mullee ${ }^{18}$ were unable to identify a control practice for their randomised trial of nurse-led asthma care. This development of structured asthma care with a focus on regular "preventer" treatment may have been one factor in the reduction of unscheduled appointments for asthma observed by Fleming et $a l^{19}$ using data from the General Practice Research Database (GPRD). This conclusion, however, must be tempered by the observation that a national survey in 2004 identified continuing high morbidity and low expectations among people with asthma. $^{3}$

Not all people with asthma want regular review or are willing to attend a prearranged appointment, with the result that annual review rates as low as $30 \%$ were, until recently, the norm. ${ }^{18}{ }^{20-22}$ Primary care researchers have explored a number of approaches to address this problem.

Targeting care to symptomatic patients was an early solution, using standard morbidity questions, which later informed the now widely adopted Royal College of Physician's three questions (RCP 3Os). ${ }^{23}{ }^{24}$ Jones et al ${ }^{23}$ posted the questions to their patients and invited those with high morbidity to attend the asthma clinic, although less than a third responded. Kemple and Rogers ${ }^{25}$ showed that including a blank asthma action plan with the clinic invitation increased the response rate from $70 \%$ to $82 \%$ among patients with asthma using an inhaled steroid.

In line with policy that advocates offering flexible modes of consultation, ${ }^{26}$ a body of work undertaken in primary care has now established a role for telephone consulting in asthma. ${ }^{13}$ Our randomised controlled trial undertaken in four UK general practices showed that conducting asthma reviews by telephone increased the proportion of 
Table 1 UK primary care research

\begin{tabular}{|c|c|c|}
\hline Key areas of research & Key contributions to clinical practice & Key areas for future research \\
\hline $\begin{array}{l}\text { Investigating innovative ways to ensure regular } \\
\text { professional review of people with asthma }\end{array}$ & $\begin{array}{l}\text { National guidelines now recommend that telephone reviews can } \\
\text { contribute to the provision of flexible support for people with } \\
\text { asthma. A key advantage is the opportunity for clinicians to } \\
\text { initiate reviews with patients who do not respond to invitations }\end{array}$ & $\begin{array}{l}\text { How can other forms of remote and/or asynchronous } \\
\text { consultation (eg, e-mail, text messaging and videophones) } \\
\text { contribute to the care of people with asthma and other long- } \\
\text { term conditions? }\end{array}$ \\
\hline $\begin{array}{l}\text { Understanding and evaluating the use of } \\
\text { technology to support patient self-care in } \\
\text { asthma and COPD }\end{array}$ & $\begin{array}{l}\text { Qualitative work and pilot studies suggest that tele-monitoring is } \\
\text { welcomed by many patients, and has the potential to support the } \\
\text { care of people with respiratory disease }\end{array}$ & $\begin{array}{l}\text { Ongoing trials will generate an evidence base to inform effective } \\
\text { and safe development of monitoring technologies. Under what } \\
\text { circumstances, and for which patient groups, does such } \\
\text { technology provide most benefit? }\end{array}$ \\
\hline $\begin{array}{l}\text { Exploring aspects of the shift of services for } \\
\text { long-term conditions from secondary to primary } \\
\text { care, including the role of GPwSI }\end{array}$ & $\begin{array}{l}\text { GPwSIs can contribute positively to the development of } \\
\text { respiratory care in their locality. Effective pulmonary rehabilitation } \\
\text { can be provided in the community by a primary health care team }\end{array}$ & $\begin{array}{l}\text { What is the impact of initiatives that aim to increase clinical } \\
\text { involvement with service development (such as Managed } \\
\text { Clinical Networks and Practice-based Commissioning) on local } \\
\text { respiratory care provision? There is a need to develop } \\
\text { interventions and test new models of care for people with } \\
\text { severe COPD }\end{array}$ \\
\hline $\begin{array}{l}\text { Investigating primary care prescribing using } \\
\text { computerised databases of anonymised } \\
\text { medical records from general practice }\end{array}$ & $\begin{array}{l}\text { There are concerns about a significant minority of adults and } \\
\text { children with asthma who are prescribed inhaled doses in excess } \\
\text { of guideline recommendations. Correlation between an increase } \\
\text { in pneumonia deaths and the reduction in antibiotic prescribing } \\
\text { raises concerns about how GPs determine the need for antibiotics }\end{array}$ & $\begin{array}{l}\text { Effective implementation of guidelines remains a challenge, and } \\
\text { better evidence-based strategies are required. How can GPs } \\
\text { target antibiotics to those most likely to benefit, thereby } \\
\text { allowing them to reduce antibiotic prescribing safely? }\end{array}$ \\
\hline $\begin{array}{l}\text { Tackling inequalities in healthcare and the } \\
\text { provision of care for ethnic minorities }\end{array}$ & $\begin{array}{l}\text { Both qualitative studies and trials highlight that effective } \\
\text { interventions do not translate directly across ethnic boundaries. } \\
\text { Practice-based screening for TB increases the detection of active } \\
\text { disease }\end{array}$ & $\begin{array}{l}\text { How to develop models of care to meet the needs of ethnic } \\
\text { minorities remains an unresolved issue }\end{array}$ \\
\hline
\end{tabular}

COPD, chronic obstructive pulmonary disease; GP, general practitioner; GpwSI, GP with special interest; TB, tuberculosis.

patients reviewed from $48 \%$ in the surgery arm to $74 \%$ of patients allocated to the telephone arm without loss of clinical effectiveness. ${ }^{27}$ The shorter duration of the telephone consultations rendered this a cost-effective intervention..$^{28}$ Feedback from patients at the end of the trial suggested that telephone consultations were welcomed as a convenient option when asthma was well controlled, whereas, if their asthma was causing concern, an in-depth face-to-face review was considered more appropriate. ${ }^{29}$

In a randomised trial in their practice, Gruffydd-Jones et al ${ }^{30}$ used a telephone call in which patients were asked the RCP 3Os to identify those whose asthma control suggested the need for a face-to-face review while offering a convenient telephone option to those currently under good control. Using this strategy, they increased the proportion reviewed from $60 \%$ to $81 \%$ with no loss of clinical control.

However, randomised controlled trials are contrived situations which take no account of patients' preference, have predetermined entry criteria (albeit relatively broad in these primary care trials; for example, we had no upper age limit and excluded only those who were housebound or unable to participate for severe medical or social reason $s^{27}$ ), and only include the subgroup of patients who consent to participate (for example, a third of eligible patients agreed to participate in our trial $^{27}$ ). The Medical Research Council's framework for the design and evaluation of complex interventions thus recommends that findings from randomised trials should be tested in a phase IV implementation trial. ${ }^{31}$

Against a background of the Quality and Outcome Framework of the 2004 General Medical Services Contract, which rewarded the provision of annual reviews for people with asthma, ${ }^{32}$ we introduced a telephone asthma review service within one group of our large practice. This offered patients the choice of a face-to-face or telephone review and enabled asthma nurses to phone non-responders opportunistically. Using anonymous patient data, we were able to test the impact of this intervention on the whole population of patients with asthma and compare the outcomes with a similar group within the practice offering the traditional clinic-based service. The provision of a telephone option within the asthma review service increased the proportion reviewed from 54\% to $66 \%$ (about half the effect size seen in the randomised trial). ${ }^{33}$ Although a fifth of patients chose a telephone review, offering a choice of mode of consultation did not increase patientinitiated appointments; however, it did enable clinicians to initiate reviews with patients who did not respond to review invitations. Asthma control was similar in both groups, but enablement and confidence in asthma management was greater in the telephone option group, reinforcing the importance of regular review in supporting self-care. ${ }^{34}$

On the basis of this work, telephone reviews are now seen by patients as contributing to the flexible support to enable them to care for their asthma, and are recommended as an option in national guidelines. ${ }^{13}$ However, in the (very near) future the rapid expanse of communication technology will demand that we understand how safely to use other forms of remote consultation including, for example, e-mail or text messages.

\section{SUPPORTING PATIENT SELF-CARE}

Communication technology is increasingly seen as a means of enabling supported self-monitoring. For example, mobile phonebased monitoring with supporting biofeedback, appears able to engage patients in their management, resulting in high levels of adherence and patient acceptability, ${ }^{35}{ }^{36}$ with many patients welcoming the innovative care. ${ }^{37}$

The theoretical model developed by Glasziou et al ${ }^{34}$ describes the complementary and evolving roles of periodic professional reviews and ongoing patient self-monitoring, citing asthma selfmonitoring as a well-defined exemplar of this concept. Our recent qualitative study suggests that people with asthma perceive a role for mobile technology in aiding transition from clinician-supported phases during which control is gained to effective self-management during maintenance phases. ${ }^{38}$ An ongoing randomised controlled trial evaluating mobile phonesupported self-management in people with asthma is currently testing this hypothesis. ${ }^{39}$

COPD is a leading cause of hospital admissions. ${ }^{40}$ Underpinned by evidence that patient recognition of COPD exacerbation symptoms followed by prompt treatment improves recovery, reduces hospitalisation risk, and is associated 
with improved quality of life, ${ }^{41}$ tele-monitoring of high-risk patients is already being implemented in some regions to support admission-avoidance schemes. ${ }^{42}{ }^{43}$ International pilot work supports this approach, showing 20-36\% fewer admissions, a $55 \%$ reduction in bed days and replacement of some nursing visits by telephone consultations informed by telemonitoring. ${ }^{44-46}$ As part of an ongoing, primary care-based programme of work, a randomised controlled trial will provide evidence of the clinical and cost effectiveness of this innovation in COPD. ${ }^{47}$

Against a background of government policy committed to developing information technology, ${ }^{48}$ such solutions to the challenges of providing care are likely to increase and evolve rapidly as technology advances and the technological literacy of both clinicians and patients increases. There will be an ongoing need to generate an evidence base to inform effective and safe development.

\section{SHIFT FROM SECONDARY TO PRIMARY CARE}

In the UK, a consistent priority for NHS reform over the last decade has been the shift from provision of hospital-based acute care to proactive care delivered in the community. ${ }^{49-51}$ Primary care research has contributed to developing an evidence base to inform a number of aspects of this reform.

Pulmonary rehabilitation has an established role in improving exercise tolerance and quality of life for people with COPD. ${ }^{52}{ }^{53}$ Jones and colleagues have pioneered the development of community-based pulmonary rehabilitation for people with COPD, demonstrating in pilot work that a "low-intensity" form of pulmonary rehabilitation performed by the primary health care team was "feasible and well received", ${ }^{44}$ and helping to define best practice. ${ }^{55} \mathrm{~A}$ particular focus of their work has been the information needs of patients with COPD. ${ }^{56}$

Guidelines emphasise the importance of providing multidisciplinary supportive care for people dying from COPD, but highlight the paucity of evidence to inform decisions. ${ }^{57}$ Primary care studies have contributed to the emerging picture of disabling symptoms, particularly shortness of breath, resulting in severe impairment of quality of life and activities of daily living and inadequate provision of holistic care. ${ }^{67-59}$ General practitioners (GPs) acknowledge the importance of discussing prognosis, although uncertainty surrounding prognosis makes this difficult in practice, and few people with end-stage COPD are offered an opportunity to discuss prognosis and make decisions about their end-of-life care. ${ }^{60} 61$ As ongoing studies further elucidate the issues, ${ }^{62}$ there is a need to develop interventions and test new models of care.

The concept of GPs with a Special Interest (GPwSIs) was initially introduced in the UK to reduce waiting lists in specific specialities. ${ }^{49}$ The General Practice Airways Group has, however, been influential in recognising the potential of primary care practitioners to have an important strategic, educational and clinical role in the delivery of specialist care for people with long-term respiratory diseases. ${ }^{63}$ Primary care research has contributed to the understanding of the multifaceted roles of respiratory GPwSIs, ${ }^{64-66}$ and recently published work has provided further insights into how primary care organisations reconfigure their workforce to provide services for people with long-term respiratory disease. ${ }^{67}{ }^{68}$ Provision of community-based pulmonary rehabilitation and leading the development of local services for people with severe COPD are practical examples of the GPwSI role.

\section{INSIGHTS FROM PRIMARY CARE DATABASES}

Computerised medical records have been the norm in primary care for two decades, with the overwhelming majority of GP practices in the UK now recording diagnostic and prescription data electronically. Consultation records and clinical data are entered on the computer using searchable Read codes, and virtually all prescribing in primary care is done electronically offering potential for the understanding of "real-world" care using computerised databases of anonymised medical records from primary care. Important examples include the GPRD, which offers 35 million patient-years of validated data collected from 450 UK general practices with over 15 years of records for individual patients (http://www.gprd.com/home), and the similar IMS Health UK Mediplus GP database (http://www. imshealth.com), DIN-Link (www.compufile.co.uk) and ORESEARCH (http://www.qresearch.org/default.aspx). Despite limitations, including the potential for omissions and inaccuracies in routinely collected data, ${ }^{69}$ there are important advantages in examining such routine data, as it reflects pragmatic influences on the behaviour of both clinicians and patients across the whole spectrum of clinical and psychosocial situations. ${ }^{70}{ }^{71}$ The perceived wisdom that observational studies overestimate treatment effects has been challenged, ${ }^{72}$ and it is suggested that cohort studies based on such databases can usefully confirm (or question) the findings of randomised trials supporting generalisability to a broad range of patients and contexts. ${ }^{70}$

As reported below, Price and colleagues have used primary care databases to explore a number of key issues related to prescribing for respiratory conditions. Over the last decade, guidelines have emphasised the safety of inhaled steroids in moderate doses, but have recommended a ceiling on the dose of inhaled steroids, preferring the addition of a long-acting $\beta$ agonist (or other add-on therapy). ${ }^{13}{ }^{14}$ Analysis of DIN-Link data in 2003 raised concerns that a quarter of adults with asthma were being prescribed "high-dose" inhaled steroids, only twothirds of whom were concurrently being prescribed add-on therapy as recommended by guidelines. ${ }^{73}$ Calculation of the average daily dose over a year confirmed these figures and identified $3.5 \%$ of the patients who were receiving doses above licensed use.

There have been a few, high-profile, cases of adrenal insufficiency in children receiving excessive doses of fluticasone, ${ }^{74}$ so the observation from a similar study in children that $4 \%$ of pre-school children and $5 \%$ of children were receiving doses equivalent to over double the recommended maximum dose of inhaled steroid is concerning. ${ }^{75}$ Only a third of children on high-dose inhaled steroids received added-on therapy. The author's conclusion that their study "highlights the over-use of high-dose inhaled corticosteroids, the under-use and inappropriate use of add-on therapy, and the use of very high and potentially dangerous doses of inhaled corticosteroids in a minority of children" is therefore important. Ekins-Daukes et $a l,{ }^{76}$ in an analysis of data from Scottish general practices, added a further dimension by calculating the total steroid load including nasal steroids in children with asthma and suggested that two-thirds of children on both treatments may be receiving excessive doses.

Epidemiological, pathophysiological and clinical studies strongly suggest a relationship between rhinitis and asthma, with surveys in primary care suggesting that $50-75 \%$ of people with asthma have symptoms of rhinitis. ${ }^{77}{ }^{78}$ Many people with rhinitis self-medicate, ${ }^{79}$ but data from the IMS Health UK Mediplus GP database suggested that adults and children with asthma who seek medical advice for their rhinitis incur greater 


\section{Key references}

- Pinnock H, Bawden R, Proctor S, et al. Accessibility, acceptability and effectiveness of telephone reviews for asthma in primary care: randomised controlled trial. BMJ 2003;326:477-9.

- Elkington H, White P, Addington-Hall J, et al. The healthcare needs of chronic obstructive pulmonary disease patients in the last year of life. Palliat Med 2005;19:485-91.

- Williams S, Ryan D, Price D, et al. General practitioners with a special clinical interest: a model for improving respiratory disease management. Br J Gen Pract 2002;52:838-43.

- Price DB, Honeybourne D, Little $\mathrm{P}$, et al. Community-acquired pneumonia mortality: a potential link to antibiotic prescribing trends in general practice. Respir Med 2004;98:17-24.

- Griffiths C, Foster G, Barnes N, et al. Specialist nurse intervention to reduce unscheduled asthma care in a deprived multiethnic area: the east London randomised control trial for high risk asthma (ELECTRA). BMJ 2004;328:144-7.

prescription charges and experience more GP attendances and hospital admissions than those with asthma alone. ${ }^{80} 81$ These findings have contributed to the increasing interest in a unified approach to managing these two conditions, as promoted by the Allergic Rhinitis and its Impact on Asthma initiative, ${ }^{82}$ and now recommended by guidelines. ${ }^{83}$

In keeping with worldwide efforts to reduce inappropriate antibiotic prescribing, data from the IMS Health UK Mediplus GP database show a 30\% decline in antibiotic prescribing for lower respiratory tract infections between winter 1994/5 and 1999/2000. Concerningly, however, comparing these data with deaths from pneumonia revealed a strong correlation $\left(R^{2}=0.85\right)$ between an increase in pneumonia deaths and the reduction in antibiotic prescribing. ${ }^{84}$ Further support for this concern is provided by an analysis of the GPRD, which showed that the risk of a diagnosis of "pneumonia" after a GP had coded a diagnosis of a "chest infection" was particularly high in elderly people and was substantially reduced by antibiotic use, with a number needed to treat of 39 for those aged $\geqslant 65 .{ }^{85}$

Recognising the rare, but important, diagnosis amid the common presentations is a familiar challenge for primary care clinicians. The detection of pneumonia in general practice is difficult, with no symptoms or signs reliably including, or excluding, the diagnosis. ${ }^{10}{ }^{86}$ The authors highlight the need for more evidence to inform GPs how to target antibiotics to those likely to benefit, allowing them to reduce antibiotic prescribing safely.

\section{TACKLING INEQUALITIES}

Primary care research conducted in the east end of London has highlighted the challenges of providing respiratory care to deprived multiethnic communities. Concerned that admission rates for South Asians were triple that for white patients, ${ }^{87}$ Griffiths and colleagues ${ }^{88}$ recruited people with asthma who had attended an accident and emergency department or been admitted with asthma in Tower Hamlets, one of the most deprived boroughs in east London. Specialist nurses provided outreach education for the practices and reviewed the patients, assessing their care and providing self-management education. Although the intervention delayed the time to first presentation with acute asthma, there was a trend towards greater benefit for white patients, echoing the findings of Moudgil and Honeybourne $e^{89}$ in a previous primary care study in Birmingham.

Qualitative work has provided insight into these findings, highlighting differences in the way South Asian and white patients cope with their asthma. ${ }^{90}$ South Asians had less confidence in their GP and often turned to family for advice in dealing with an exacerbation. They had less understanding of the role of preventive medication or the use of oral steroids in an exacerbation. However, some anticipated factors (such as language barriers, socioeconomic differences) did not appear to be significant. Organisation of care varied substantially between practices in this deprived inner city area, with some practices encouraging specialist nurses to act autonomously, whereas others left the nurses feeling marginalised and consequently unable to contribute productively ${ }^{91}$

In order to address some of these issues, Griffiths et a ${ }^{92}$ developed and tested a culturally adapted lay-led self-management programme for Bangladeshi adults with a range of chronic diseases including asthma. The programme improved selfefficacy and self-management behaviour, but did not have a significant effect on use of healthcare. How best to adapt existing models of care to meet the needs of South Asian people with asthma therefore remains an unresolved issue. ${ }^{93} 94$

The increasing incidence of tuberculosis, especially in migrant populations, has raised interest in appropriate screening procedures. Qualitative interviews with immigrants confirm the acceptability of screening and suggested that, to maximise uptake, screening should be provided in a variety of settings, including primary care..$^{95}$ In a subsequent cluster randomised controlled trial, an outreach programme promoted screening for tuberculosis in patients registering with practices in Hackney, and increased the detection of active tuberculosis. ${ }^{96}$

\section{CONCLUSIONS}

Primary care respiratory research has contributed to the evidence base for both the clinical care of common long-term respiratory conditions and the management of acute respiratory illness. The increasing challenge of providing support for people with long-term conditions will demand innovative approaches to organisation of care, many of which will involve or be led by primary care. Further research is needed in all these areas.

\section{MULTIPLE CHOICE QUESTIONS (TRUE (T)/FALSE (F); ANSWERS AFTER THE REFERENCES)}

\section{Innovative ways to ensure regular professional review of people with asthma}

A. Nurse-led asthma care has been shown in randomised controlled trials to result in a reduction in unscheduled appointments

B. About a third of people with asthma will respond to an invitation to attend for a routine review

C. Conducting asthma reviews by telephone increased the proportion of patients reviewed from a half to threequarters compared with surgery reviews

D. The Quality and Outcome Framework of the 2004 GMS Contract rewards the provision of 6-monthly reviews for people with asthma

E. Offering an asthma review service that included a telephone option increased enablement and confidence in asthma management 


\section{Organisation of care for long-term conditions}

A. The main role of general practitioners (GPs) with a special interest in respiratory care is to provide a clinical referral service

B. Uncertainty surrounding prognosis of chronic obstructive pulmonary disease (COPD) is a key barrier to offering people with end-stage COPD an opportunity to discuss end-of-life issues

C. Pulmonary rehabilitation improves lung function for people with COPD

D. Pulmonary rehabilitation for people with COPD can be provided by the primary health care team in the community

E. Mobile phone-based monitoring of asthma is associated with high levels of adherence and patient acceptability

\section{Using computerised databases of anonymised medical records from general practice}

A. Cohort studies based on routinely collected data can support the generalisability of randomised controlled trial evidence to a broad range of patients and contexts

B. Over the course of a year, a quarter of adults prescribed inhaled steroids are receiving doses above licensed use

C. Over $50 \%$ of people with asthma have symptoms of rhinitis

D. One in 39 people over the age of 65 diagnosed by their GP with a "chest infection" actually has pneumonia

E. In 2000 , only $30 \%$ of people who consulted their GP with a lower respiratory tract infection were prescribed antibiotics

\section{Tackling inequalities in healthcare and the provision of care for ethnic minorities}

A. Admission rates for South Asians with asthma were triple that for white patients

B. Specialist nurse interventions reduced time to admission equally in both South Asians and white patients

C. Language barriers and socioeconomic differences were important factors in how South Asian patients coped with their asthma

D. Lay-led self-management programmes for Bangladeshi adults improved self-efficacy and self-management behaviour

E. Involvement of inner city general practices in screening for tuberculosis in newly registered patients increased the detection of active tuberculosis

Acknowledgements: HP is supported by a Primary Care Research Career Award from the Chief Scientist's Office, Scottish Government. We thank Professor David Price, Professor Chris Griffiths and Dr Rupert Jones for their helpful advice on an earlier draft of this review.

Competing interests: None.

\section{REFERENCES}

1. British Thoracic Society. Burden of lung disease. 2nd edn. London: British Thoracic Society, 2006.

2. Smith NM. The 'Needs of people with asthma' survey and initial presentation of the data. Asthma J 2000:5:133-7.

3. Haughney J, Barnes G, Partridge M, et al. The Living \& Breathing study: a study of patients' views of asthma and its treatment. Prim Care Respir J 2004;13:28-35.

4. Juniper EF, Chauhan A, Neville E, et al. Clinicians tend to overestimate improvements in asthma control: an unexpected observation. Prim Care Respir J 2004;13:181-4.

5. Skilbeck J, Mott L, Page $\mathrm{H}$, et al. Palliative care in COPD: a needs assessment. Palliative Med 1998;12:245-54.

6. Elkington $\mathbf{H}$, White $\mathrm{P}$, Addington-Hall $\mathrm{J}$, et al. The last year of life of COPD: a qualitative study of symptoms and services. Respir Med 2004:98:439-45.
7. Gore JMM, Brophy CJ, Greenstone MA. How well do we care for patients with end stage chronic obstructive pulmonary disease (COPD)? A comparison of palliative care and quality of life in COPD and lung cancer. Thorax 2000;55:1000-6.

8. The Respiratory Alliance. Bridging the gap. 2003. http://www.gpiag.org/news/ bridging.php (accessed 27 Jan 2009).

9. Department of Health. Improving chronic disease management. London: Department of Health, 2004

10. Scottish Intercollegiate Guideline Network. Community management of LRTI. Edinburgh: SIGN, 2002.

11. Levy ML, Stephenson P, Barritt P, et al. The UK General Practice Airways Group (GPIAG): its formation, development, and influence on the management of asthma and other respiratory diseases over the last twenty years. Prim Care Respir $J$ 2007; 16:132-9.

12. International Primary Care Respiratory Group. Research needs statement Aberdeen: IPCRG, 2008. http://www.theipcrg.org/resneeds/resneeds.php laccessed 27 Jan 2009).

13. The British Thoracic Society/Scottish Intercollegiate Guideline Network. British guideline on the management of asthma. Thorax 2008;63(Suppl 4):1-121.

14. Global Initiative for Asthma. Global strategy for asthma management and prevention. GINA, 2007. http://www.ginasthma.org (accessed 27 Jan 2009)

15. Barnes G. Nurse-run asthma clinics in general practice. J Coll Gen Pract 1985;35:447

16. Charlton I, Charlton G, Broomfield J, et al. Audit of the effect of a nurse run asthma clinic on workload and patient morbidity in a general practice. Br J Gen Pract 1991:41:227-31.

17. Department of Health and the Welsh Office. General practice in the National Health Service: a new contract. London: HMSO, 1989.

18. Jones KP, Mullee MA. Proactive, nurse run asthma care in general practice reduces asthma morbidity: scientific fact or medical assumption? Br J Gen Pract 1995; 45:497-9

19. Fleming DM, Sunderland R, Cross KW, et al. Declining incidence of episodes of asthma: a study of trends in new episodes presenting to general practitioners in the period 1989-98. Thorax 2000;55:657-61.

20. Price D. Wolfe S. Delivery of asthma care: patient's use of and views on healthcare services, as determined from a nationwide interview survey. Asthma J 2000;5:141-4.

21. Gruffydd-Jones K, Nicholson I, Best L, et al. Why don't patients attend the asthma clinic? Asthma Gen Pract 1999:7:36-8.

22. Nolan D, White P. Symptomatic asthma: attendance and prescribing in general practice. Respir Med 2002;96:102-9.

23. Jones $\mathbf{K}$, Clearly $\mathrm{R}$, Hyland $\mathrm{M}$. Predictive value of a simple asthma morbidity index in a general practice. Br J Gen Pract 1999;49:23-6.

24. Pearson MG, Bucknall CE, eds. Measuring clinical outcome in asthma: a patient focussed approach. London: Royal College of Physicians, 1999

25. Kemple T, Rogers C. A mailed personalised self-management plan improves attendance and increases patients' understanding of asthma. Prim Care Respir 2003;12:110-14.

26. Department of Health. Building on the best: choice, responsiveness and equity in the NHS. London: DoH, 2003.

27. Pinnock H, Bawden R, Proctor S, et al. Accessibility, acceptability and effectiveness of telephone reviews for asthma in primary care: randomised controlled trial. BMJ 2003; 326:477-9.

28. Pinnock H, McKenzie L, Price D, et al. Cost effectiveness of telephone or surgery asthma reviews: economic analysis of a randomised controlled trial. Br J Gen Pract 2005;55:119-24.

29. Pinnock H, Madden V, Snellgrove C, et al. Telephone or surgery asthma reviews? Preferences of participants in a primary care randomised controlled trial. Prim Care Respir J 2005;14:42-6.

30. Gruffydd-Jones $\mathbf{K}$, Hollinghurst $S$, Ward $S$, et al. Targeted routine asthma care in general using telephone triage. Br J Gen Pract 2005;55:918-23.

31. Campbell M, Fitzpatrick R, Haines A, et al. Framework for design and evaluation of complex interventions to improve health. BMJ 2000;321:694-6.

32. NHS Confederation, British Medical Association. New GMS Contract 2003 investing in general practice. London: BMA, March 2003.

33. Pinnock H, Adlem L, Gaskin S, et al. Accessibility, clinical effectiveness and practice costs of providing a telephone option for routine asthma reviews: controlled implementation study. Br J Gen Pract 2007;57:714-22.

34. Glasziou $\mathbf{P}$, Irwig L, Mant D. Monitoring in chronic disease: a rational approach. BMJ 2005;330:644-8.

35. Ryan D, Cobern W, Wheeler J, et al. Mobile phone technology in the management of asthma. J Telemed Telecare 2005;11(Suppl 1):43-6.

36. Cleland J, Caldow J, Ryan D. Attitudes of patients and staff to using mobile phone technology to record and gather asthma data: a qualitative study. J Telemed Telecare 2007;13:85-9.

37. Pinnock H, Slack R, Pagliari $\mathrm{C}$, et al. Professional and patient attitudes to using mobile phone technology to monitor asthma: questionnaire survey. Prim Care Respir J 2006;15:237-45.

38. Pinnock H, Slack R, Pagliari C, et al. Understanding the potential role of mobile phone based monitoring on asthma self-management: qualitative study. Clin Exp Allergy 2007;3:794-802.

39. Ryan D, Pinnock H, Tarassenko L, et al. Mobile phone based structured intervention to achieve asthma control in patients with uncontrolled persistent asthma: pragmatic randomised controlled trial. Asthma UK. Project ID: 07/047. http://www.asthma.org. uk/researchers/research database/index.html (accessed 27 Jan 2009). 
40. Damiani M, Dixon J. Managing the pressure: emergency hospital admissions in London, 1997-2001. London: King's Fund, 2002.

41. Wilkinson T, Donaldson GC, Hurst JR, et al. Early therapy improves outcomes of exacerbations of chronic obstructive pulmonary disease. Am J Respir Crit Care Med 2004;169:1298-303.

42. Institute for Innovation and Development. Telehealth in Kent: what's behind its success? London: NHS, 2007.

43. Dale J, Connor S, Tolley K. An evaluation of the West Surrey telemedicine monitoring project. Telemed Telecare 2003;9(S):39-41.

44. Casas A, Troosters T, Garcia-Aymerich J, et al. Integrated care prevents hospitilisations for exacerbations in COPD patients. Eur Respir J 2006;28:1-8.

45. de Toledo P, Jimenez S, del Pozo F, et al. Telemedicine experience for chronic care in COPD. IEEE transactions on Information Technol Biomed 2006:10:567-72.

46. Trappenburg JCA, Niesink A, Weert-van Oene GH, et al. Effects of telemonitoring in patients with chronic obstructive pulmonary disease. Telemedicine e-Health 2008; 14:138-46

47. McKinstry B, Pinnock $\mathrm{H}$, Hanley J, et al. Telemetric supported self-monitoring of long-term conditions: telemetric supported self-monitoring of COPD: randomised controlled trial. Chief Scientist Office: NHS Applied Research Programme Grant. 2008. http://www.sehd.scot.nhs.uk/cso/ (accessed 27 Jan 2009).

48. Department of Health. Delivering 21st century IT support for the NHS: national strategic programme. London: Department of Health, 2002.

49. Department of Health. The NHS Plan: a plan for investment, a plan for reform. London: The Stationery Office, 2000.

50. Department of Health. The NHS Improvement Plan: putting people at the heart of public services. London: The Stationery Office, 2004.

51. Department of Health. Our health, our care, our say: a new direction for community services. London: The Stationery Office, 2006.

52. Lacasse $\mathbf{Y}$, Goldstein R, Lasserson TJ, et al. Pulmonary rehabilitation for chronic obstructive pulmonary disease. Cochrane Database Syst Rev 2006;(4):CD003793.

53. National Institute for Clinical Excellence. National clinical guideline management of chronic obstructive pulmonary disease in adults in primary and secondary care. Thorax 2004;59(Suppl 1):S1-232.

54. Jones RCM, Copper S, Riley 0 , et al. A pilot study of pulmonary rehabilitation in primary care. Br J Gen Pract 2002;52:567-8.

55. Backley J, Bloom J, Bott J, et al. A summary of recommendations of the pulmonary rehabilitation in the community: sharing best practice meeting. GPIAG, 2005. www. gpiag.org (accessed 27 Jan 200).

56. Hyland M, Jones R, Hanney K. The Lung Information Needs Questionnaire: development, preliminary validation and findings. Respir Med 2006;100:1807-16.

57. Elkington $\mathbf{H}$, White $\mathrm{P}$, Addington-Hall J, et al. The healthcare needs of chronic obstructive pulmonary disease patients in the last year of life. Palliat Med 2005; 19:485-91.

58. Seamark DA, Blake SD, Seamark CJ. Living with severe COPD: perceptions of patients and their carers. Palliat Care 2004:18:619-25.

59. Seamark D, Seamark C, Halpin D. Palliative care in chronic obstructive pulmonary disease: a review for clinicians. J $R$ Soc Med 2007;100:225-33.

60. Elkington $\mathbf{H}$, White $\mathrm{P}$, Higgs $\mathrm{R}$, et al. GPs' views of discussions of prognosis in severe COPD. Fam Pract 2001;18:440-4.

61. Mulcahy P, Buetow S, Osman L, et al. GPs' attitudes to discussing prognosis in severe COPD: an Auckland (NZ) to London (UK) comparison. Fam Pract 2005;22:538-40.

62. Pinnock H, Murray S, Worth A, et al. A breath of fresh air: improving care and services for patients living and dying with chronic obstructive pulmonary disease, and their carers. Project ID: CZH 4 320. Chief Scientists Office, 2006

63. Williams S, Ryan D. Price D, et al. General practitioners with a special clinical interest: a model for improving respiratory disease management. Br J Gen Pract 2002; 52:838-43.

64. Gilbert R, Franks G, Watkin S. The proportion of general practitioner referrals to a hospital respiratory medicine clinic suitable to be seen in a GPwSI respiratory clinic. Prim Care Respir J 2005;14:314-19.

65. Pinnock H, Netuveli G, Price D, et al. General practitioners with a special interest in respiratory medicine: national survey of primary care organisations. BMC Health Serv Res 2005:5:40.

66. Moffat M, Sheikh A, Price D, et al. Can a GP be a generalist and a specialist? Stakeholders views on a respiratory general practitioner with a special interest service in the UK. BMC Health Serv Res 2006:6:62.

67. Pinnock H, Huby G, Powell A, et al. The process of planning, development and implementation of a General Practitioner with a Special Interest service in primary care organisations in England and Wales: a comparative prospective case study. Report for the National Co-ordinating Centre for NHS Service Delivery and Organisation R\&D Programme. London. http://www.sdo.nihr.ac.uk (accessed 27 Jan 2009).

68. Hamilton S, Huby G, Tierney A, et al. Mind the gap between policy imperatives and service provision: a qualitative study of the process of respiratory service development in England and Wales. BMC Health Serv Res 2008:8:248.

69. Lawrenson RA, Coles $\mathrm{G}$, Walton $\mathrm{K}$, et al. Characteristics of practices contributing to the MediPlus database and the implications for its use in epidemiological research. J Inform Prim Care 1998 May:14-18.
70. Thomas M, Cleland J, Price D. Database studies in asthma pharmacoeconomics: uses, limitations and quality markers. Expert Opin Pharmacother 2003:4:351-8.

71. Anandan C, Simpson CR, Fischbacher C, et al. Exploiting the potential of routine data to better understand the disease burden posed by allergic disorders. Clin Exp Allergy 2006;36:866-71

72. Benson K, Hartz AJ. A comparison of observational studies and randomised controlled trials. N Engl J Med 2000;342:1878-86.

73. Thomas $\mathbf{M}$, Leather D, Price D. High-dose inhaled corticosteroids and add-on therapy use in adults with asthma in the UK in 2003: an observational study. Prim Care Respir J 2006:15:166-72.

74. Drake AJ, Howell RJ, Shield JPH, et al. Symptomatic adrenal insufficiency presenting with hypoglycaemia in asthmatic children with asthma receiving high dose inhaled fluticasone propionate. BMJ 2002;324:1081-3.

75. Thomas M, Turner S, Leather D, et al. High-dose inhaled corticosteroid use in childhood asthma: an observational study of GP prescribing. Br J Gen Pract 2006;56:788-90.

76. Ekins-Daukes S, Simpson CR, Helms P, et al. Burden of corticosteroids in children with asthma in primary care: retrospective observational study. BMJ 2002:324:1374.

77. Walker S, Sheikh A. Self-reported rhinitis is a significant problem for patients with asthma: results from a national (UK) survey. Prim Care Respir J 2005;14:83-7.

78. Yawn BP, Yunginger JW, Wollan PC, et al. Allergic rhinitis in Rochester, Minnesota residents with asthma: frequency and impact on health care charges. J Allergy Clin Immunol 1999:103:54-9.

79. Richards S, Thornhill D, Roberts $\mathrm{H}$, et al. How many people think they have hay fever and what they do about it. Br J Gen Pract 1992;42:284-6.

80. Thomas $\mathbf{M}$, Turner $\mathrm{S}$, Leather $\mathrm{D}$, et al. Asthma-related health care resource use among asthmatic children with and without concomitant allergic rhinitis. Pediatrics 2005;115:129-34.

81. Price D, Zhang 0, Kocevar VS, et al. Effect of a concomitant diagnosis of allergic rhinitis on asthma-related health care use by adults. Clin Exp Allergy 2005;35:282-7.

82. Bachert C, van Cauwenberge P, Khaltaev N, et al. Allergic rhinitis and its impact on asthma. In collaboration with the World Health Organization. Executive summary of the workshop report. Allergy 2002;57:841-55.

83. Scadding GK, Durham SR, Mirakian R, et al. BSACl guidelines for the management of allergic and non-allergic rhinitis. Clin Exp Allergy 2007;38:19-42.

84. Price DB, Honeybourne D, Little P, et al. Community-acquired pneumonia mortality: a potential link to antibiotic prescribing trends in general practice. Respir Med 2004; 98:17-24.

85. Petersen I, Johnson A, Islam A, et al. Protective effect of antibiotics against serious complications of common respiratory tract infections: retrospective cohort study with the UK General Practice Research Database. BMJ 2007;335:982-4.

86. Metlay JP, Kapoor WN, Fine MJ. Does this patient have community acquired pneumonia? Diagnosing pneumonia by history and physical examination. JAMA 1997:278:1440-5

87. Netuveli G, Hurwitz B, Levy M, et al. Ethnic variations in UK asthma frequency, morbidity, and health-service use: a systematic review and meta-analysis. Lancet 2005;365:312-17

88. Griffiths C. Foster G. Barnes N et al. Specialist nurse intervention to reduce unscheduled asthma care in a deprived multiethnic area: the east London randomised control trial for high risk asthma (ELECTRA). BMJ 2004;328:144-7.

89. Moudgil H, Honeybourne D. Differences in asthma management between white European and Indian subcontinent ethnic groups living in socio economically deprived areas in the Birmingham (UK) conurbation. Thorax 1998:53:490-4.

90. Griffiths C, Kaur G, Gantley M, et al. Influences on hospital admission for asthma in south Asian and white adults: qualitative interview study. BMJ 2001;323:962-6.

91. Foster G, Gantley M, Feder G, et al. How do clinical nurse specialists influence primary care management of asthma? A qualitative study. Prim Care Respir $\mathrm{J}$ 2005; 14:154-60.

92. Griffiths C, Motlib J, Azad A, et al. Randomised controlled trial of a lay-led selfmanagement programme for Bangladeshi patients with chronic disease. $\mathrm{Br} \mathrm{J}$ Gen Pract 2005; 55:831-7.

93. Simpson CR, Sheikh A. Understanding the reasons for poor asthma outcomes in ethnic minorities: welcome progress, but important questions remain. Clin Exp Allergy 2007:37:1730-2.

94. Sheikh A, Griffiths C. Tackling ethnic inequalities in asthma. We now need results. Respir Med 2005:99:381-3.

95. Brewin $\mathbf{P}$, Jones $\mathrm{A}$, Kelly $\mathbf{M}$, et al. Is screening for tuberculosis acceptable to immigrants? A qualitative study. J Public Health 2006;28:253-60.

96. Griffiths C, Sturdy P, Brewin P, et al. Educational outreach to promote screening for tuberculosis in primary care: a cluster randomised controlled trial. Lancet 2007;369:1528-34.

\footnotetext{
Answers

(A) F; (B) T; (C) T; (D) F; (E) T

2. (A) $F ;(B) T ;(C) F ;(D) T ;(E) T$

3. (A) $\mathrm{T}$; (B) $\mathrm{F} ;(\mathrm{C}) \mathrm{T}$; (D) $\mathrm{F}$; (E) $\mathrm{F}$

4. (A) $\mathrm{T}$; (B) F; (C) F; (D) T; (E)
} 